More Information

\title{
Maculopapular delayed exanthema due to ranitidine
}

\section{Pilar Hernández Alfonso*, Idoia González Mahave, Irene Vidal Oribe, $M^{\mathrm{a}}$ Dolores del Pozo Gil, Mónica Venturini Díaz and Teófilo Lobera Labairu}

Allergy Department, CARPA-San Millán Hospital, Logroño, La Rioja, Spain

\section{Abstract}

Ranitidine is a widely used drug in Europe and its intake is usually well tolerated. Hypersensitivity reactions due to ranitidine are uncommon. The immediate mild reactions type are the most prevalent. In some special cases a delayed type reaction such as contact dermatitis or severe reactions with systemic involvement have been reported.

In the present paper, a case report of a 78-year old patient who experienced a maculopapular eruption after 7 days of oral treatment with ranitidine is described. Patch tests were performed twice with ranitidine with positive results confirming the diagnosis. In order to discard a double sensitization and a possible cross-reactivity phenomenon, patch test was performed once with famotidine, with a negative result. This is the first maculopapular exanthema reported as type IV hypersensitivity reaction to ranitidine confirmed by patch testing.

Moreover, there are only two reported cases showing a double sensitization to ranitidine and to other $\mathrm{H} 2$-receptor antagonists by patch testing after a delayed reaction due to ranitidine, the other being $\mathrm{H} 2$-receptor antagonists involving cimetidine and nizatidine, not famotidine.

\begin{abstract}
*Address for Correspondence:
Pilar Hernández Alfonso, Allergy Department, CARPA-San Millán Hospital. C/Obispo Lepe S/N 26004, Logroño, La Rioja, Spain, Tel: +34 647169 047; 941298000; Email: phernandeza@riojasalud.es; pilarha93@gmail.com

Submitted: December 08, 2020 Approved: December 22, 2020 Published: December 23, 2020

How to cite this article: Alfonso $\mathrm{PH}$, Mahave IG, Oribe IV, del Pozo Gil MD, Díaz MV, et al. Maculopapular delayed exanthema due to ranitidine. Ann Dermatol Res. 2020; 4: 014-016.
\end{abstract}

DOI: 10.29328/journal.adr.1001012

ORCiD: orcid.org/0000-0003-0465-5656

Copyright: () 2020 Alfonso PH, et al. This is an open access article distributed under the Creative Commons Attribution License, which permits unrestricted use, distribution, and reproduction in any medium, provided the original work is properly cited.

Keywords: Antisecretory function; Crossreactivity; Delayed reaction; Famotidine; Hypersensitivity; Maculopapular exanthema; Patch test; Ranitidine

(D) Check for updates

open Access

\section{Introduction}

Ranitidine is an H2-receptor antagonist with an important antisecretory function. It is used as one of the main treatments for gastric pathologies involving high levels of gastric acid as gastroesophageal-reflux, Zollinger-Ellison Syndrome or peptic ulcer [1]. The use of oral tablets of ranitidine [2,3] has been dramatically reduced due to the report published in 2019 by the AEMPS (Agencia Española Del Medicamento y Productos Sanitarios) where they pointed out the presence of traces of NDMA (N-Nitrosodimethyamine), a carcinogenic component, in its composition.

Hypersensitivity reactions to ranitidine are rare and most are of a IgE-mediated type I reaction. Symptoms usually appear within the first hour after the intake of the drug, ranging from mild to anaphylaxis [4]. Reported delayed reactions are severe, systemic reactions [5-9] or contact occupational dermatitis due to environmental ranitidine exposure $[10,11]$. In this publication we present an unusual form of delayed hypersensitivity reaction to ranitidine, a maculopapular eruption without systemic involvement diagnosed by patch testing. Only one case of a similar reaction has been found in publish literature and the diagnose was carried out by lymphocyte stimulation test [5]. Patch testing with famotidine was also performed with a negative result.

\section{Case report}

A 78-year-old man with cardiovascular risk factors and a recent ischemic stroke. A week after starting treatment with clopidogrel, enoxaparin, metformin and ranitidine, the patient came to the hospital with a generalized pruritic maculopapular eruption consisting of patches of red skin covered with small and confluent papules distributed over the neck, thorax, abdomen, back and proximal region of the extremities. No presence of general symptoms or mucosal involvement were observed. A high temperature peak was notified 24 hours before the start of the cutaneous manifestations, the patient was referred to the hospital where previous medications were discontinued and corticosteroids and antihistamines were administered. A few days after, the eruption improved. A month after, when the patient was studied in our department, the eruption was resolved.

Blood tests were performed and no abnormalities were found. Hepatic enzymes, blood series and inflammatory 
parameters were in the normal range. Epicutaneous tests were carried out with the standard battery of GEIDAC (Spanish Group for the Investigation of Contact Dermatitis and Skin Allergies), adding standard batteries of gastric protectors, heparins, clopidogrel and metformin. Results were interpreted at 48 hours and 96 hours according to the recommended criteria of the International Contact Dermatitis Research Group. The results were negative for all drugs tested, except for ranitidine, which showed an intense positive result at 48 hours and at 96 hours (Figure 1).

A month after, patch tests were repeated with ranitidine and famotidine (both at 30\% concentration in petrolatum base). Ranitidine results showed an intense positive result at 48 hours and an extremely strong positive result at 96 hours (Table 1). Famotidine results were negative.

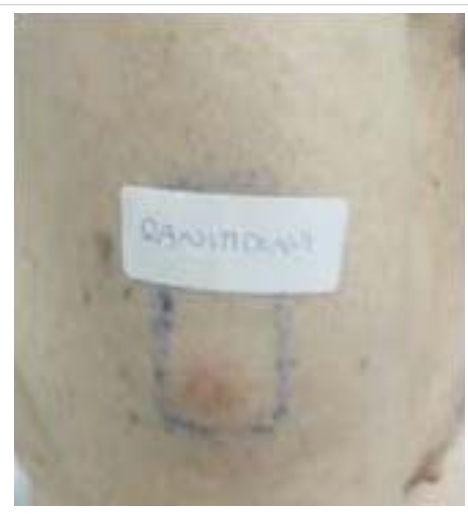

Figure 1: Positive intense result on patch test at 48 hours.

Table 1: Results of ranitidine and famotidine patch tests.

\begin{tabular}{|l|l|l|l|l|l|}
\hline $1^{\circ} \mathrm{PT}$ & $\mathbf{4 8}$ hours & 96 hours & $2^{\circ} \mathrm{PT}$ & 48 hours & 96 hours \\
\hline Ranitidine & ++ & ++ & Ranitidine & ++ & +++ \\
\hline Famotidine & NP & NP & Famotidine & - & - \\
\hline
\end{tabular}

First performance $\left(1^{\circ} \mathrm{PT}\right)$ and second one $\left(2^{\circ} \mathrm{PT}\right)$ carried out one month later. ${ }^{*} \mathrm{PT}$ : Patch Test. *NP: Not performed.

Negative controls were performed with famotidine patch tests. Ten patients with no history of allergy to either famotidine or ranitidine were selected. All results were negative. Neither cimetidine nor nizatidine were tested. These drugs were not available at the pharmacy department of our hospital because they are not commercialized in our country.

\section{Discussion}

Ranitidine is a well-tolerated drug and highly used in Europe $[4,14]$. Hypersensitivity reactions are unusual, most of them are immediate type reactions, usually expressed as mild manifestations such as pruritus or acute maculopapular eruptions without other systemic symptoms $[17,18]$. Nonetheless, severe reactions such anaphylaxis or angioedema [15-17] have been reported.

However, in some cases, delayed reactions have been observed: occupational allergic contact dermatitis due to environmental exposure to ranitidine $[10,11]$ or even severe reactions with systemic involvement such as DRESS syndrome (Drug Reaction with Eosinophilia and Systemic Symptoms) [7], TEN (Toxic Epidermal Necrolysis) [6] or AGEP (Acute Generalized Exanthematous Pustulosis) [9]. Allergic contact dermatitis cases and delayed severe reactions previously named $[7,9]$ were confirmed with epicutaneous tests.

In publish literature, one delayed type IV maculopapular eruption without systemic involvement has been reported and the diagnosis was confirmed by an intense reaction in a drug- induced lymphocyte stimulation test [5].

We show the first reported case of maculopapular drug eruption by ranitidine, classified as a delayed type reaction and confirmed by epicutaneous tests. We want to emphasize that a hypersensitivity type IV process was involved, and an intense positive response was observed on two separate occasions by patch tests to confirm the sensitization.

The patch test was composed of a $30 \%$ ranitidine concentration diluted in a petrolatum base, but there are also reported positive results on patch tests with ranitidine, with a $1 \%-5 \%$ concentration diluted in petrolatum base $[7,9,10]$.

A famotidine patch test was performed to evaluate a possible cross reactivity phenomenon between ranitidine and famotidine, but no sensitization to famotidine could be demonstrated by patch testing. Only two cases have been published reporting cross-reactivity between ranitidine and other anti-H2 drugs (nizatidine [13] and cimetidine [7]) by patch testing. To the knowledge of the authors, there are no cases showing positive patch tests to famotidine and ranitidine at the same time.

An oral challenge test with famotidine was not performed due to the availability of other alternative drugs, in case the patient required antacid treatment. Therefore, we couldn't assure a safe intake of famotidine, so the patient was advised to completely avoid any anti- $\mathrm{H} 2$ drugs.

Some studies have reported that the differences between the rings on the chemical structure of these anti-H2 drugs are considerable, the furan ring of the ranitidine is the main sensitizing moiety of this medicine. Ranitidine was designed by replacing the imidazole ring of cimetidine with a furan ring. Meanwhile famotidine was structured by replacing the imidazole ring with a 2-guanidinothiazole ring [14,12,13,18]. In addition, it is suggested that there are possible crossreactivity among drugs in this group due to similarities found on their lateral chains $[14,18]$.

In conclusion, we show an unusual case of cutaneous allergy due to ranitidine. To our knowledge, this is the first case reported of a delayed type allergy of a maculopapular exanthema, confirmed by patch testing.

\section{Acknowledgment}

We acknowledge the Allergy Department of Logroño for helping with the clinical study and diagnosis. 


\section{References}

1. Grant SM, Langtry HD, Brogden RN. An updated review of its pharmacodynamic and pharmacokinetic properties and therapeutic use in peptic ulcer disease and other allied diseases. Drugs. 1989; 37: 801-870. PubMed: https://pubmed.ncbi.nlm.nih.gov/2667937/

2. Revisión de los medicamentos que contienen ranitidina por la presencia de nitrosaminas [Internet]. Asociación Española de Mediacamentos y Productos Sanitarios. 2020. https://www.aemps.gob.es/

3. Mahase E. Ranitidine: patients taking certain batches should "immediately discontinue use," says FDA. BMJ. 2019; 17053.

4. Foti C, Cassano N, Panebianco R, Calogiuri G, Vena G. Hypersensitivity reaction to ranitidine: Description of a case and review of the literature. Immunopharmacol Immunotoxicol. 2009; 31: 414-416.

PubMed: https://pubmed.ncbi.nlm.nih.gov/19694603/

5. Okamoto O, Fujiwara S. Drug eruption caused by ranitidine hydrochloride (Zantac) which showed a strong reaction in a druginduced lymphocyte stimulation test. J Dermatol. 2007; 34: 74-79. PubMed: https://pubmed.ncbi.nlm.nih.gov/17204107/

6. Vérez A, Motreno JC. Second case of ranitidine related toxic epiderma necrolysis in a patient with idiopathic Thrombocytopenic purpura J Am Acad Dermatol. 2000; 42: 305.

PubMed: https://pubmed.ncbi.nlm.nih.gov/10642697/

7. Watts T, Haque R. DRESS Syndrome Induced by Ranitidine. The Journa of Allergy and Clinical Immunology: In Practice. 2018; 6: 1030-1031. PubMed: https://pubmed.ncbi.nlm.nih.gov/29102410/

8. Palacios-Zabalza I, Camino-Rodríguez E, Aguirre C. Síndrome de Kounis inducido por ranitidina. Medicina Clínica. 2018; 151: e51-e53.

9. Blanes Martínez M, Silvestre Salvador JF, Vergara Aguilera G, Betlloch Mas I, Pascual Ramirez JC. Acute generalized exanthematous pustulosis induced by ranitidine hydrochloride. Contact Dermatitis. 2003; 49-47. PubMed: https://pubmed.ncbi.nlm.nih.gov/14641127/
10. Ryan PJ, Rycroft RJ, Aston IR. Allergic contact dermatitis from occupational exposure to ranitidine hydrocloride. Contact Dermatitis. 2003; 48: 67-68.

PubMed: https://pubmed.ncbi.nlm.nih.gov/12694207/

11. Herrera-Mozo I, Sanz-Gallen P, Martí-Amengual G. Occupational contact allergy to omeprazole and ranitidine. Medycyna Pracy. 2017; 68: 433-435

PubMed: https://pubmed.ncbi.nlm.nih.gov/28512370/

12. Song W, Kim M, Lee S, Kwon Y, Kim S, et al. Two Cases of H2 Receptor Antagonist Hypersensitivity and Cross-Reactivity. Allergy, Asthma and Immunology Research. 2011; 3: 128-131. PubMed: https://www.ncbi.nlm.nih.gov/pmc/articles/PMC3062792/

13. Morisset M, Moneret-Vautrin DA, Loppinet V, Grandidier S. Crossallergy to ranitidine and nizatidine. Allergy. 2000; 55: 682-683. PubMed: https://pubmed.ncbi.nlm.nih.gov/10921476/

14. Bocșan IC, Sabin O, Matei D, Muntean A, Buzoianu AD. How often we diagnose allergy to ranitidine? Eur Rev Med Pharmacol Sci. 2020; 24: 10812-10818.

PubMed: https://pubmed.ncbi.nlm.nih.gov/33155242/

15. Dwivedi S, Chopra D, Arora P, Khan S. Anaphylaxis following intravenous ranitidine: A rare adverse reaction of a common drug. Indian J Pharmacol. 2014; 46: 234-236.

PubMed: https://pubmed.ncbi.nlm.nih.gov/24741203/

16. Mori F, Barni S, Pecorari L, Sarti L, Pucci N, et al. Anaphylaxis to Intravenous Ranitidine in a Child. Pharmacology. 2015; 95: 240-242. PubMed: https://pubmed.ncbi.nlm.nih.gov/25967233/

17. Yilmaz I, Turk M. Ranitidine-Induced Anaphylaxis in a Patient with Acute COPD Exacerbation. Turk Thorac J. 2017; 18: 94-95. PubMed: https://pubmed.ncbi.nlm.nih.gov/29404169/

18. Bossi A, Romeo G, Pezzoli A. Side-effects, structure, and H2-receptor antagonists. Lancet. 1992; 339: 1366.

PubMed: https://pubmed.ncbi.nlm.nih.gov/1350041/ 